Article

\title{
Evaluation of Barriers of Corporate Social Responsibility Using an Analytical Hierarchy Process under a Fuzzy Environment-A Textile Case
}

\author{
Lixin Shen ${ }^{1}$, Kannan Govindan ${ }^{2, *}$ and Madan Shankar ${ }^{3}$ \\ 1 Transportation Management College, Dalian Maritime University, Dalian 116026, China; \\ E-Mail: shenlixin@dlmu.edu.cn
}

2 Department of Business and Economics, University of Southern Denmark, Odense 5230, Denmark

3 Department of Mechanical Engineering, PTR College of Engineering, Madurai 625008, India; E-Mail: mshankar@ptr.ac.in

* Author to whom correspondence should be addressed; E-Mail: gov@sam.sdu.dk; Tel.: +45-6550-3188; Fax: +45-6550-3237.

Academic Editor: Tsan-Ming Choi

Received: 29 October 2014 / Accepted: 3 March 2015 / Published: 23 March 2015

\begin{abstract}
The ventilating crisis of Corporate Social Responsibility (CSR) issues in the textiles industry resulted in the engagement of many researchers in the analysis of CSR and its related factors throughout the globe. Some researchers in developed nations extend their policies beyond the boundary of CSR in the textiles industry, but some developing contexts are still limited to this boundary, including India, due to facts that have not yet been revealed. Hence, to fill this gap, this study reveals the factors that are resisting the implementation of CSR in the textiles industry with the assistance of a proposed model, and this model is validated with a case industry situated in southern India. Common barriers are collected through various reliable means, and among those common barriers, the essential barrier was identified with the assistance of the case industrial manager through an Analytical Hierarchy Process (AHP) under a fuzzy environment. The results show that financial constraints comprise the main barrier to the implementation of CSR in the Indian textiles industry, which is then further validated with feedback from case industry managers. This study offers both societal and scientific insights, identifies limitations, and provides an approach that may be extended in the future once additional factors are implemented.
\end{abstract}

Keywords: barriers of CSR; fuzzy AHP; Indian textiles 


\section{Introduction}

Recent business trends have put pressure on organizations and stakeholders to proactively adopt sustainable strategies, because businesses realize that economic advantage alone does not benefit them in the long-term market. With modern globalization and industrialization, organizations are more likely to implement sustainable strategies, such as corporate social responsibility (CSR). CSR became popular due to its capacity to embrace all dimensions of sustainability, whereas other sustainable strategies may have limitations or may fail [1,2]. Corporate social responsibility is nothing but a sustainable strategy, but it has no standard definition. For instance Dahlsrud [3] provides thirty-six definitions for CSR; in addition, other researchers and practitioners offer different definitions based on their own experiences and perceptions. CSR is applicable to various industries throughout the globe, including manufacturing, automobiles, supply chains, pharmaceuticals, textiles, and so on. Among industrial sectors, the textiles industry garners significant attention regarding its workability issues, which include the balance of workers' resources and their work demands [4]. Recently, the textiles industry has faced a huge crisis over CSR issues, so researchers and practitioners are actively engaged in finding solutions for these societal issues.

Among sustainable strategies, CSR is a prominent strategy that deals effectively with workability issues and societal issues within the firm [5]. In textile industries located within developed nations, CSR strategies have been successfully implemented. However, in developing nations - such as South Asia - such strategies have not succeeded almost certainly due to various hidden factors. Hence, this study attempts to investigate the factors that resist the successful implementation of CSR in the Indian textile sector. Few studies have so far attempted to analyze CSR issues in Indian textile sectors. For instance, Gupta and Hodges [6] explore consumer perceptions of CSR within the Indian textile sector, and De Neve [7] analyzes the flexibility of CSR in a South Indian garments firm in the Tirupur region. Dash et al. [8] explores the organizational culture and environmental responsibilities in the Indian textile industry. Baskaran et al. [9] evaluates the best supplier based on the issue of sustainability in Indian textile sectors. Baskaran et al. [10] also compares the sustainable supplier assessment within the Indian automotive and textile industrial sectors. However, these studies are limited only to common CSR issues and strategies in the textile industry; they do not analyze the specific barriers that serve as the primary threats to CSR implementation.

Some studies do consider CSR barriers within Indian and other scenarios [11-16], but these studies have limitations. Some pursue different sectors other than the Indian textile industry. Furthermore, according to Govindan et al. [17], CSR is still an unclear strategy within the Indian context because the implementation gap is high. Hence, to fill this research gap, this study evaluates the essential barriers for successful implementation of CSR, and from among the common CSR barriers in the Indian textile sector, we determine the priority barrier with the assistance of multi-criteria decision-making (MCDM) tools, namely, a Fuzzy AHP. Common barriers are collected from various sources and those barriers are then evaluated through the proposed model with the assistance of a case industry; subsequently, the results are validated with feedback from case industrial managers.

The remaining sections are as follows. Section 2 provides a review of existing literatures to identify prominent research already conducted on this paper's central objective, the barriers of CSR, the research gaps and highlights. A problem description and a relevant proposed model framework are explained in 
Section 3. Section 4 provides the solution methodology for the problem, and an application and validation of the proposed model is illustrated with an Indian case study in Section 5. Sections 6 and 7 discuss results and managerial contributions, respectively, and a conclusion is given in Section 8 .

\section{Literature Review}

This section seeks to detail the basic preliminaries used in this research along with the literature support. This section categorizes three subsections, namely: CSR, barriers of CSR, and CSR in the textile industry. Subsection 1 discusses the origin of CSR, Subsection 2 analyzes the existing literature and focuses on the barriers in the implementation of CSR, and Subsection 3 clears the current status of CSR in textile industries with literature backup. A detailed description of each subsection follows.

\subsection{CSR}

Whereas many definitions exist in the current realm of social literature, one of the most well-defined and frequently cited definition of CSR is provided by the Commission of the European Communities [18]: "Corporate social responsibility is about companies having responsibilities and taking actions beyond their legal obligations and economic/business aims. These wider responsibilities cover a range of areas, but are frequently summed up as social and environmental — where social means society broadly defined, rather than simply social policy issues. This can be summed up as the triple bottom line approach: i.e., Economic, social and environmental". The history of CSR extends as far back as 1930, when two Harvard University professors, A.A. Berle and C.G. Means, introduced the concept in their book The Modern Corporation and Private Property in 1930 [17,19,20]. The concepts of CSR have continually evolved and are still actively debated. As a result, many studies apply the concept of CSR to different sectors, for instance, to food industries [21,22], educational institutions [23,24], automobile sectors [25,26], apparel and textile industries [27-29], pharmaceutical [30,31] and so on. While much debate focuses on improving the effective implementation of CSR, the basic need for improvement substantiates the idea that CSR is neither clearly understood nor effectively implemented. Because many definitions of CSR exist, social researchers naturally promote the definition that best pertains to their own application of interest. When conflicting dimensions exist at the core of CSR, practitioners are unduly pressured by these various approaches. Hence, because the concept itself is a challenge both to define and to implement, a necessary first step is to identify the challenges. This study utilizes the resource-based view theory for identifying the barriers of CSR, proposed by Wernerfelt in 1984 [32]. While the clear identification of factors reflects a good result, a due to the multiple dimensions and conflicting factors involved in the CSR as mentioned above, a well-defined methodology is needed to prioritize conflicting multidimensional factors. Many methodologies exist to analyze these conflicting factors, and the multi-criteria decision-making (MCDM) model offers a beneficial approach for the controversial and conflicting terms within CSR. For example, according to Von Neumann and Morgenstern [33], Savage [34], and Zavadskas et al. [35], MCDM became one of the key paradigms to support managerial decisions, particularly those made in order to analyze multi dimension parameters and also to consider conflicting social factors [35]. From the review of MCDM methodologies, it is affirmed that no specific steps are followed in terms of theoretical perspective in decision making; instead, every study proceeds and defines with its own concepts according to the field of application, an 
approach also affirmed by Zavadskas et al. [35]. Hence, the MCDM methodology is used in this study to analyze the challenging factors associated with the implementation of CSR particularly within the concern of the Indian textile sector. Due to the unsolvable CSR issues that still exist, the livelihood of the Indian people in internships, jobs, health, environment, labor standards, and other areas of concern, is still directly affected. Many studies [6,9,36-38] affirm that the Indian textile sector still suffers shortcomings in the effective implementation of CSR.

\subsection{Barriers of CSR}

The above subsection reviewed fundamental difficulties in the history and definition of CSR. With those difficulties in mind, this subsection seeks to review the factors and barriers associated with the implementation of CSR.

Factors that impede and challenge the implementation of CSR in an organization are called barriers. One approach to identifying such barriers is to correlate them to a firm's size. Laudal [16] analyzed the drivers and barriers of CSR and then compared the transformation of these factors within small- and medium-scale enterprises (SMEs) and multinational enterprises based on a literature survey of relevant papers. Sweeney [14] explored the opportunities and barriers of CSR in Irish origin with the assistance of a literature survey and semi-structured interviews. He also compared the position of both opportunities and barriers of CSR between the large firms and SMEs.

Some studies particularly analyze the barriers of CSR implementation with a national perspective. For instance, Valmohammadi [39] explored the understandings of a CSR domain and concepts in an Iranian context along with a detailed analysis of CSR drivers and barriers. In this study, he particularly focused on a code of conduct named "ISO 26000," and he narrowed his analysis to seven core issues: organizational governance, human rights, labor practices, the environment, fair operating practices, consumer issues, and community involvement and development. This study was supported with 105 responses received from Iranian organizations. Duarte and Rahman [40] detailed the perceptions of CSR among Bangladeshi managers, in which definition current initiatives and barriers of CSR within the manager's perspective were explored through face-to-face interviews. Arevalo and Aravind [12] explored the practices of CSR in an Indian context along with its approaches, drivers, and barriers. As a result of the data collected from their sample of companies currently engaged in CSR, they determined four types of CSR approaches: the ethical, the statist, the liberal, and the stakeholder.

Some studies investigated the supply chain in analyzing the barriers of CSR. Mont and Leire [41] discussed the barriers and drivers of CSR in supply chains using the term socially responsible purchasing under the concerns of Swedish origin. In addition, they identified the critical factors for socially responsible purchasing in supply chain management. Faisal [13] analyzed the barriers of corporate social responsibility in supply chain management using the MCDM tool of interpretive structural modeling. He explored the interrelationship and interdependencies among the barriers of CSR in supply chain management. Parisi et al. [42] conducted a literature review on factors that motivate and restrict the implementation of CSR in supply chain management. Finally, whereas certain studies focused on barriers without any constraints, Garavan et al. [15] analyzed the behavioral barriers of CSR and corporate sustainability (CS) with the concern of human resource development. 


\subsection{CSR in Textile Industry}

Once CSR issues began to be raised in textile sectors, researchers were forced to explore new tactics, which resulted in an increased number of research articles, some of which examined developing nations and others that focused on developed nations. For instance, Chi [28] analyzed the development, achievements, and challenges of CSR practices in the Chinese textile and apparel industry. He also extended the topic with a consideration of supply chains. Cooke and He [29] connected the terms human resource management and corporate social responsibility in the Chinese textile and apparel industry through the perception of the managers regarding these two terms. Pedersen et al. [43] investigated the institutional pressures of CSR within the Nordic fashion industry with the assistance of responses from 400 fashion companies in Denmark, Norway, Sweden, Finland, and Iceland. From this study, they finalized that the pressures are not central to those nations but rather they differ among various stakeholder groups. Goworek [44] explored the social and environmental issues involved in the clothing industry through a case study adapted in UK. Gupta and Hodges [6] investigated the consumers' perceptions on CSR in the Indian apparel industry through in-depth interviews with Indian respondents; they concluded by revealing the importance of CSR in decision making in the Indian apparel industry. Kozar and Connell [45] analyzed the relationship between social and environmental responsibility by examining, through data collected from online questionnaires, the attitudes, knowledge, and purchasing behavior in apparel and textile related industries. Ha-Brookshire and Norum [46] investigated the factors that influence the willingness of the customers to pay premium prices for socially responsible products such as organic cotton, sustainable cotton, and US-grown cotton shirts; their data was collected from 500 respondents. Dickson and Eckman [47] conducted a study on social responsibility from the perspectives of apparel and textile scholars; 87 members of the International Textile and Apparel Associations (ITAA) participated. Perry and Towers [27] investigated the antecedents of CSR in smalland medium-scale enterprises in the UK fashion garment manufacturing industry.

\subsection{Research Gap and Highlights}

From a review of the above literatures, currently no work has attempted to evaluate the barriers involved in the implementation of corporate social responsibility. Some researchers have explored barriers, but such studies are limited to textile application sectors where major CSR issues exist, and, furthermore, most of these studies did not specifically consider an Indian origin. Due to this lack of exploration in the Indian textile sector with the consideration of CSR implementation, many Indian organizations have suffered a loss in their reputations and standards in the global marketplace. If Indian textile sectors do not meet the codes of conduct found in developed nations, their organizations will be in chaos as they try to enact strategies designed to defend CSR barriers. An initial step is to determine which factors serve as barriers of CSR in the industry. Hence, this study has developed a methodological approach to identify the essential barriers that hinder Indian textile industrial managers from performing an effective implementation of CSR. We identify common barriers involved in CSR implementation and we evaluate an essential barrier. The highlights of this research are further detailed below.

- Common barriers of corporate social responsibility are identified through a review of existing literatures and recommendations from technical experts. 
- A model framework has been proposed with fuzzy multi-criteria decision-making (MCDM) approach to reveal the essential barrier and the priorities among barriers of CSR implementation.

- The model framework was applied in an Indian textile industry (case industry) to validate the model and also to assist their industrial managers to disseminate their essential barrier in the implementation of CSR in their organization.

- The results obtained from the case study are further explored by comparing them with existing literatures and through feedback from case industrial experts and managers.

\section{Problem Description}

Due to the demand for CSR, many academicians and researchers seek to establish a clear definition of CSR activities, because for many industries and applications, its definition is still elusive [48-51]. Recently, many organizations have felt free to implement CSR in wider arenas, and Indian textile industries, in particular, have worked hard to enact CSR. Over the last two decades, India's textile sector has expanded from a largely domestic market to the global marketplace, and this broader business environment has required the adoption of modern workplace strategies. Those required business strategies include ethical and social responsibilities, keeping costs low, offering just-in-time delivery, and shortening lead times, etc. [36]. No firm, whether it is a large or a medium scale textile industry, can escape these business pressures; all seek to balance effective productivity and social responsibilities while maintaining a strong position in the competitive business market. Despite significant pressures on Indian textile manufacturers with regard to CSR, Baskaran et al. [9,10] finds that Indian textile organizations are still able to implement CSR successfully. This study attempts to analyze the vital factors that hinder the implementation of CSR in Indian textile industries. For instance, an important process in the textile industry is the dyeing of cloth. But wastewater from the dyeing process is dumped into the river. This wastewater contaminates ground water, which, in turn, results in soil contamination and may easily give rise to human health defects. In September 2013, the Gujarat Pollution Control Board provided a closure notice to 8 textile industries for violating the law; these industries used prohibited material as fuel. In addition, the Board posted notices to 37 textile and printing units to reclaim their ownership [52].

Another business practice found too often in textile industries is forced overtime work. Because it is common for nations with higher populations to have fewer job opportunities, workers often feel forced to accept overtime work. The result is an increase in workers' personal tension, which may easily lead to great health risk. These examples illustrate just a few of the potential difficulties involved in implementing CSR effectively in Indian textile industries. Businesses face difficult challenges, so this study analyzes the ways in which CSR implementation is problematic within Indian textile industries. To analyze these CSR barriers, a model framework is proposed, shown in Figure 1.

To achieve the aim of this research, the model framework provided in Figure 1 is proposed to narrow the path and methodology of the research. Figure 1 forms a flowchart that begins with data collection completed through the assistance of existing literatures and from the notions of technical experts. Common barriers are collected first through existing literatures, and then they are presented for examination to experts within the textile industry. Once the common barriers are finalized with the help of the team of experts, then the identified barriers are rated with the help of a case industry and supported by their industrial managers. Their linguistic replies are then converted into numerical values and these 
values are processed with the assistance of multi-criteria decision-making methodology, which is then further interpolated with fuzzy approach to avoid uncertainties and inaccuracies that may arise due to human judgments. Further, these fuzzy data sets are converted to defuzzified values and a final ranking will be made. This ranking will be validated through the consistency check to ensure the reliability of data. Next, the results are explored and compared with literature resources and discussed with industrial managers to validate the obtained results. Significant conclusions will be made once the primary effective barrier of CSR implementation in Indian textile sectors is determined. The most common barriers are shown in Table 1.

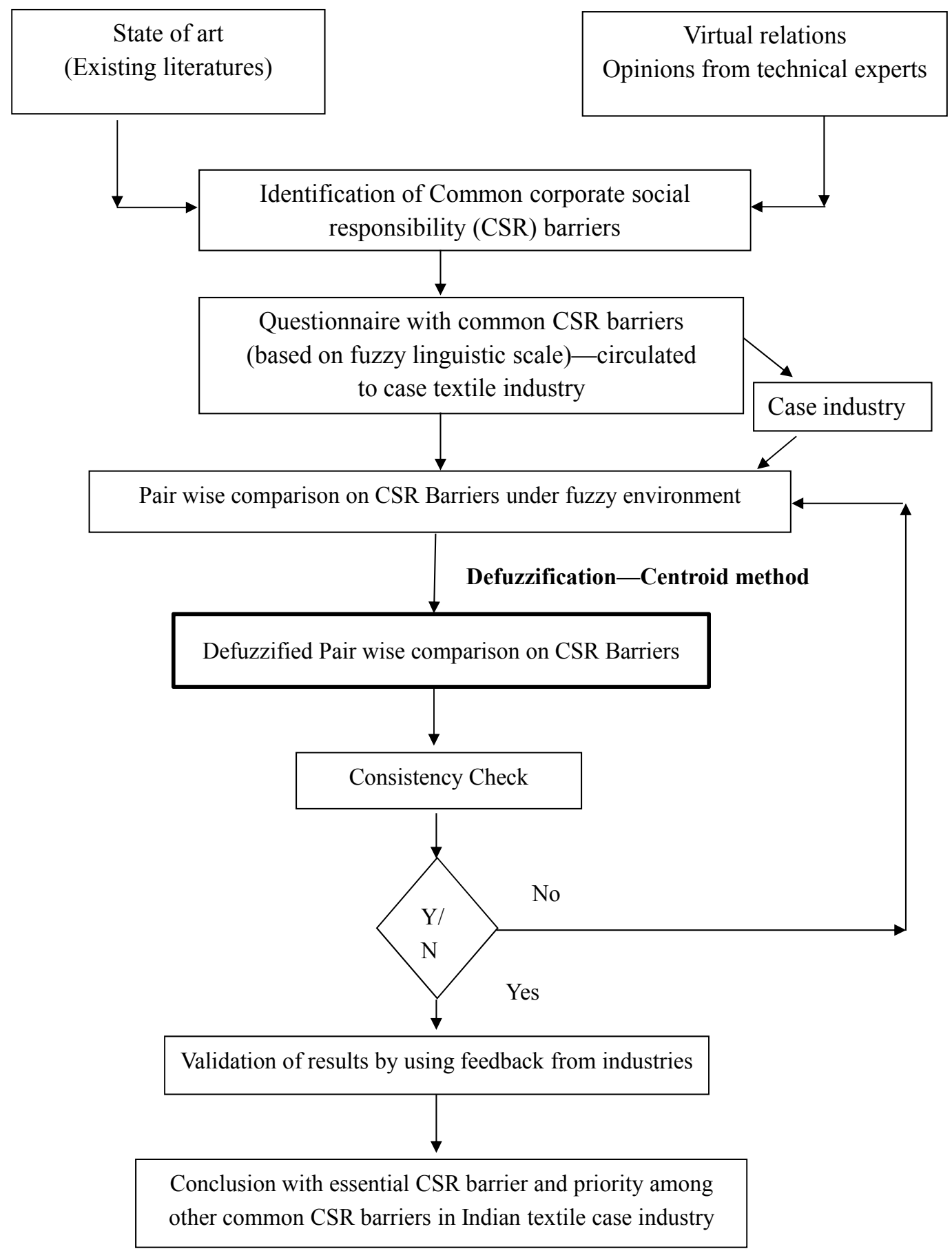

Figure 1. Proposed framework for evaluating the barriers of corporate social responsibility (CSR) in Indian textile industry. 
Table 1. Common barriers of corporate social responsibility (CSR) implementation.

\begin{tabular}{|c|c|c|c|}
\hline S. No & Barriers of CSR in Textile Industry & Explanation & Reference \\
\hline 1 & Lack of stakeholder awareness (B1) & $\begin{array}{l}\text { In developing nations, the unhealthy establishment of CSR and lack of ethical awareness } \\
\text { keeps the stakeholders uninformed as to CSR implementation. }\end{array}$ & {$[39,40]$} \\
\hline 2 & Lack of training (B2) & $\begin{array}{l}\text { In order to practice CSR, managers, employees and all other individuals in the organization } \\
\text { should have relevant training to foster a strategic implementation of CSR. }\end{array}$ & {$[10,40]$} \\
\hline 3 & Lack of information (B3) & $\begin{array}{l}\text { Because CSR is potentially difficult to define, acquiring relevant information regarding CSR } \\
\text { presents challenges and slows down effective implementation. }\end{array}$ & {$[39,40]$} \\
\hline 4 & Financial constraints (B4) & $\begin{array}{l}\text { Due to the lack of financial support, organizational managers find that implementing CSR } \\
\text { cannot fit their budgets; the initial investment cost is too high. }\end{array}$ & {$[10,40]$} \\
\hline 5 & Lack of customer awareness (B5) & $\begin{array}{l}\text { Indian customers are more likely to go for economical profit rather than quality and } \\
\text { other societal parameters. This motivates the manufacturers to focus on profits only. }\end{array}$ & {$[39,40]$} \\
\hline 6 & Lack for concern for reputation (B6) & $\begin{array}{l}\text { While some well-equipped organizations are aware of the importance of their industry's reputation } \\
\text { and its impact on competitive advantage, some small scale and developing organizations do not } \\
\text { realize the value of their reputation. As a result, they are not motivated to implement CSR. }\end{array}$ & [40] \\
\hline 7 & Lack of knowledge (B7) & $\begin{array}{l}\text { Due to the lack of training and information, the CSR practices are poorly understood in many } \\
\text { organizations, and this lack of knowledge on CSR among practitioners creates challenges. }\end{array}$ & {$[39,40,53]$} \\
\hline 8 & Lack of regulations and standards (B8) & $\begin{array}{l}\text { Unlike EU and US, the rules and laws are not very clearly established in the developing countries, } \\
\text { which freely allows the stakeholders to avoid the CSR. }\end{array}$ & [40] \\
\hline 9 & Diversity (B9) & $\begin{array}{l}\text { CSR has multi faces, which change from origin to origin, nation to nation and so on. This diversity } \\
\text { restricts the practitioners from understanding how to implement the CSR based on their origin. }\end{array}$ & [40] \\
\hline 10 & Company culture (B10) & $\begin{array}{l}\text { Some organizations, relying on old company culture, are resistant to changing } \\
\text { to new strategies like CSR }\end{array}$ & {$[40]$} \\
\hline 11 & Lack of social audit (B11) & $\begin{array}{l}\text { Lack of social audit is one of the barriers for CSR which allows the stakeholders } \\
\text { to be exempt from CSR reporting. }\end{array}$ & [40] \\
\hline 12 & $\begin{array}{l}\text { Lack of top management } \\
\text { commitment (B12) }\end{array}$ & Some of the top level managers only focus on financial profit rather than societal benefit. & {$[40]$} \\
\hline
\end{tabular}




\section{Solution Methodology}

While there are many multi-criteria decision-making (MCDM) tools, the analytical hierarchy process (AHP) garners more interest due to its accuracy and effectiveness over results, an approach first discussed by Saaty in 1980 [54]. It is a measurement theory assisted by pairwise comparisons based on replies from experts [55]. The AHP skillfully assists both decision makers and managers through its decomposition, comparative judgment, and synthesis of priorities [56-58]. In addition, Dyer and Forman [59] proposed several advantages, as follows: (I) it can solve problems that have tangible, intangible, individual, and shared values; (II) it can assist decision makers in focusing on objectives rather than on alternatives; and (III) it allows for every factor to be considered in turn because it divides each problem into its own structural hierarchy [58]. Accompanying these substantial impacts, decision-making aided by AHP likely increases a firm's reasonableness and comprehensiveness [60,61].

The AHP model is a useful MCDM tool, but one must recognize that it relies on judgments made by humans; as such, these judgments frequently have a high level of vagueness and uncertainty. To reduce the degree of uncertainty, Chang [62] developed a system that introduces triangular fuzzy numbers as a means to reduce uncertainty factors and to increase the level of accuracy. Generally, fuzzy numbers utilize three numbers 1, m, u as shown in Figure 2. Many studies [63-68] have successfully applied this fuzzy integration into their methodology due to its greater reliability, and this study also integrates the fuzzy theory into the AHP approach.

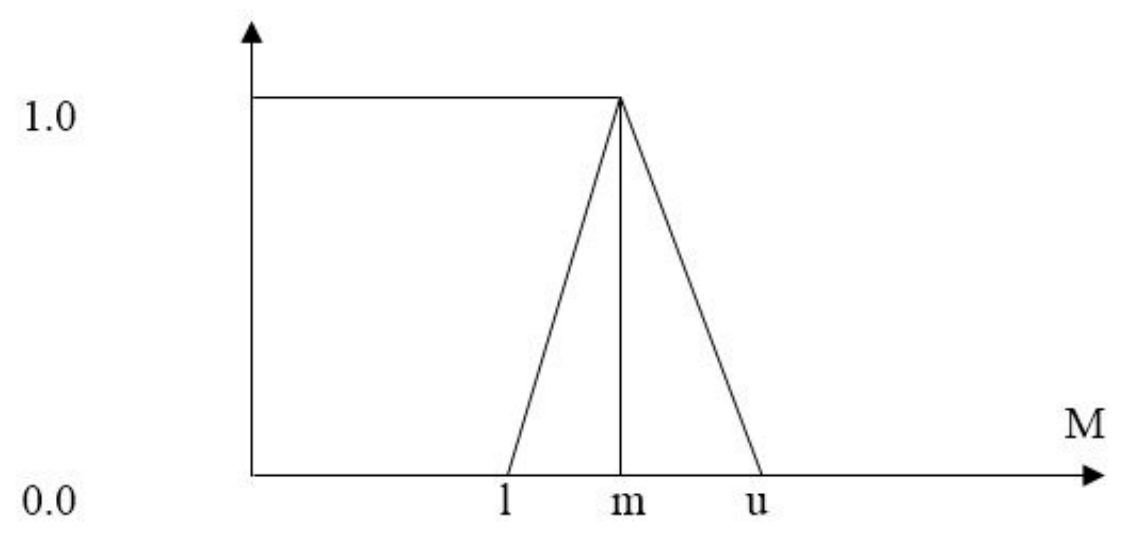

Figure 2. Triangular fuzzy numbers $[61,69]$.

The steps to use fuzzy AHP are as follows (adapted from [61]):

Step 1: Identification of common attributes

The first step of Fuzzy AHP is to identify the common attributes of the problem. Special importance should be addressed towards precision and reliability of the defined attributes, because the study solely depends upon these attributes and a misconception of these attributes leads to a failure of the research model.

\section{Step 2: Set up pairwise comparisons under fuzzy environment}

Once the attributes related to the problem are clearly defined, the next step is to make a pairwise comparison among the common attributes: one over and another under the fuzzy environment. To set up this fuzzy pairwise comparison, managers from the case industry to be approached are presented with a 
comparative questionnaire. If, for instance, attribute " $\mathrm{X}$ " is rated and compared with attribute " $\mathrm{Y}$ " in the Saaty scale, the managers are asked to establish how many times more important attribute " $\mathrm{X}$ " is over attribute "Y" within the Saaty scale limit. From the replies of the industrial managers, every attribute of the problem will be compared and this linguistic comparison gets converted into the fuzzy pairwise relation matrix. The formation of the pairwise comparison is shown in Equation (1). The fuzzy matrix $\tilde{A}\left(\mathrm{a}_{\mathrm{ij}}\right)$ is summarized below:

$$
\widetilde{\boldsymbol{A}}=\left[\begin{array}{cccccc}
1 & \mathrm{a}_{12} & \mathrm{a}_{13} & \ldots . & \mathrm{a}_{1(\mathrm{n}-1)} & \mathrm{a}_{1 \mathrm{n}} \\
\mathrm{a}_{21} & 1 & \mathrm{a}_{23} & \ldots . & \mathrm{a}_{2(\mathrm{n}-1)} & \mathrm{a}_{2 \mathrm{n}} \\
\ldots . & \ldots . & \ldots . & \ldots . & \ldots . & \ldots . \\
\ldots . & \ldots . & \ldots . & \ldots & \ldots . & \ldots \\
\mathrm{a}_{(\mathrm{n}-1) 1} & \mathrm{a}_{(\mathrm{n}-1) 2} & \mathrm{a}_{(\mathrm{n}-2) 3} & \ldots . & 1 & \mathrm{a}(\mathrm{n}-1) \mathrm{n} \\
\mathrm{an}_{\mathrm{n} 1} & \mathrm{a}_{\mathrm{n} 2} & \mathrm{a}_{\mathrm{n} 3} & \ldots . & \mathrm{a}_{\mathrm{n}(\mathrm{n}-1)} & 1
\end{array}\right]
$$

where,

$$
\tilde{a}_{\mathrm{ij}}=\left\{\begin{array}{c}
\mathrm{i}=\mathrm{j} \\
1,3,5,7,9 \text { or } 1 / 1, \frac{1}{3}, \frac{1}{5}, \frac{1}{7}, \frac{1}{9} \\
\mathrm{i} \neq \mathrm{j}
\end{array}\right.
$$

\section{Step 3: Defuzzification}

In the previous step, the pairwise comparison was made up of fuzzy numbers; so then these triangular fuzzy numbers are converted into crisp numbers. The conversion of fuzzy numbers into crisp numbers is called defuzzification. While many types of defuzzification methods exist, this study uses the centroid method of defuzzification for its well-known acceptance.

Step 4: Estimation of global weights

The defuzzified pairwise comparison obtained from the previous step will be processed through various standard arithmetic operations of formal AHP to find the global weights of each attribute. The arithmetic calculations involved in the formal AHP are listed below.

(I) Standardize the defuzzified pairwise comparison matrix (all values in the matrix should lie between 0 and 1 ).

(II) Calculate the eigenvalue ( $\mathrm{x}$ ) with the assistance of the sum of standardized rows. The eigenvalue is nothing but the global weight of each attribute.

\section{Step 5: Check for consistency}

Because the data is based purely on human judgments, which naturally include difference, the results must be validated. Thus, the priorities of the criteria and the relevant steps are checked for consistency. The cyclic process is repeated until the consistency index (C.R) is less than 0.1 .

The following steps provide the consistency check for the pairwise comparison matrix [63]

(1) Calculate the eigenvector or relative weights and $\lambda_{\max }$ for each matrix of order $n$

(2) Compute the consistency index for each matrix of order $n$ by the formulae:

$$
\mathrm{CI}=\left(\lambda_{\max }-n\right) /(n-1)
$$


(3) The consistency ratio is then calculated using the formulae:

$$
\mathrm{CR}=\mathrm{CI} / \mathrm{RI}
$$

Table 2 shows the random index used in the consistency check. This index depends on " $n$ " which denotes the number of criteria. For instance, in this problem twelve barriers are investigated; hence, $n=12$ and the corresponding (Random Index) R.I is 1.48 .

Table 2. Random index for corresponding number of criteria.

\begin{tabular}{cccccccccccc}
\hline $\mathbf{1}$ & $\mathbf{2}$ & $\mathbf{3}$ & $\mathbf{4}$ & $\mathbf{5}$ & $\mathbf{6}$ & $\mathbf{7}$ & $\mathbf{8}$ & $\mathbf{9}$ & $\mathbf{1 0}$ & $\mathbf{1 1}$ & $\mathbf{1 2}$ \\
\hline 0.00 & 0.00 & 0.58 & 0.90 & 1.12 & 1.24 & 1.32 & 1.41 & 1.45 & 1.49 & 1.51 & 1.48 \\
\hline
\end{tabular}

\section{Step 6: Prioritization of attributes}

Once the consistency is achieved, then the attributes are prioritized based on their weights, and from this priority the essential attribute will be identified.

\section{Application of Proposed Framework}

The proposed methodology for identifying the essential barrier of CSR is applied in the case industry through two phases, namely, the identification of common barriers and then an evaluation of the essential barrier of CSR through fuzzy AHP. Located in the southern part of India, the case industry occupies an area of 3.25 hectares and they have over 20 years industrial experience. Many researchers have explored Indian scenarios in recent years, such as those who examined drivers of reverse logistics [70], and enablers of green supply chains [71]. In order to maintain a competitive position in the marketplace, industries recognize that they must focus on CSR. Hence, they accepted the research team approach designed to analyze and to evaluate the factors that serve as barriers for CSR implementation. With the assistance of the case industry, this methodology was adapted which was further elaborated as follows.

Phase I: Identification of common barriers of CSR in the Indian textile industry

To achieve the aim of this phase, our research team secured assistance from both virtual and state-of-the-art worlds, including existing literature resources and technical experts in the relevant field. The literature review employed the search terms "CSR", "corporate social responsibility in textile industry", "barriers of CSR in textile industry", from reputable databases such as Elsevier, Springer, Emerald, Taylor and Francis, and others. In addition, some grey literatures were also considered based on their relevancy to this problem as suggested by the research experts. The CSR barriers collected from the existing literatures were shown to the technical experts to gauge their initial responses, and from this introductory step, a one-day workshop was arranged. For this one-day workshop, an invitation was sent to 120 large-scale textile companies in the southern part of India. Sixty-two replies were returned, demonstrating a $51.66 \%$ response rate. Those interested industrial managers were then called and invited to the workshop. The first session of the workshop outlined the detailed concepts and reiterated the need for the research to those managers. In the second session, the barriers that were collected from the literature review were circulated, and the industrial managers were asked to check whether they were currently facing these common barriers. If they answered affirmatively, they were asked to explain how and why, and if they answered negatively, we requested that they explain how. In addition, the managers 
were encouraged to add any other barrier that was not mentioned in the circulated barriers but that they faced in their organizations. Finally, in the third session, the collected CSR barriers from Session two were compiled, thus creating the common barriers of CSR implementation in the Indian textile sector along with the existing literature support. The identified common barriers are shown in Table 1.

Phase II: Evaluation of essential barrier of CSR in textile industry through Fuzzy AHP

Once the common barriers are identified, the next phase is to then evaluate the essential barrier of CSR through fuzzy AHP. The steps of fuzzy AHP are adapted and detailed in the solution methodology section.

Step 1: Identification of common barriers

The common barriers of CSR in the Indian textile industry were already performed and tabulated in Phase I.

\section{Step 2: Set up pairwise comparison under fuzzy environment}

Once the common barriers are identified, then a pairwise comparison among the barriers, one over another, under the fuzzy environment is established. To achieve this, the case industrial managers were contacted and a questionnaire was provided. Based on their replies, the pairwise comparison was made. The replies of the industrial managers are in the form of linguistic preferences, which were further converted to fuzzy inputs with the references shown in Table 3.

Table 3. Linguistic terms and the corresponding triangular fuzzy numbers [72].

\begin{tabular}{cc}
\hline Linguistic Term & Positive Triangular Fuzzy Scale (l, m, u) \\
\hline Extreme unimportance & $(1 / 10,1 / 9,1 / 8)$ \\
Intermediate value & $(1 / 9,1 / 8,1 / 7)$ \\
Very unimportant & $(1 / 8,1 / 7,1 / 6)$ \\
Intermediate value & $(1 / 7,1 / 6,1 / 5)$ \\
Essential unimportance & $(1 / 6,1 / 5,1 / 4)$ \\
Intermediate value & $(1 / 5,1 / 4,1 / 3)$ \\
Moderate unimportance & $(1 / 4,1 / 3,1 / 2)$ \\
Intermediate value & $(1 / 3,1 / 2,1)$ \\
Equally important & $(1,1,1)$ \\
Intermediate value & $(1,2,3)$ \\
Moderate importance & $(2,3,4)$ \\
Intermediate value & $(3,4,5)$ \\
Essential importance & $(4,5,6)$ \\
Intermediate value & $(5,6,7)$ \\
Very vital importance & $(6,7,8)$ \\
Intermediate value & $(7,8,9)$ \\
Extremely vital importance & $(8,9,10)$ \\
\hline
\end{tabular}

The converted pairwise comparison of barriers one over another in fuzzy environment is shown in Table 4. 
Table 4. Pairwise comparison of barriers under fuzzy environment.

\begin{tabular}{|c|c|c|c|c|c|c|c|c|c|c|c|c|}
\hline & B1 & B2 & B3 & B4 & B5 & B6 & B7 & B8 & B9 & B10 & B11 & B12 \\
\hline $\mathrm{B} 1$ & $(1,1,1)$ & $(1 / 4,1 / 3,1 / 2)$ & $(1 / 3,1 / 2,1)$ & $(1,2,3)$ & $(2,3,4)$ & $(2,3,4)$ & $(2,3,4)$ & $(1 / 3,1 / 2,1)$ & $(2,3,4)$ & $(3,4,5)$ & $(1 / 3,1 / 2,1)$ & $(1 / 3,1 / 2,1)$ \\
\hline B2 & $(2,3,4)$ & $(1,1,1)$ & $(1,2,3)$ & $(1 / 3,1 / 2,1)$ & $(1 / 3,1 / 2,1)$ & $(3,4,5)$ & $(2,3,4)$ & $(1 / 3,1 / 2,1)$ & $(6,7,8)$ & $(3,4,5)$ & $(1 / 3,1 / 2,1)$ & $(1 / 3,1 / 2,1)$ \\
\hline B3 & $(1,2,3)$ & $(1 / 3,1 / 2,1)$ & $(1,1,1)$ & $(1 / 3,1 / 2,1)$ & $(1 / 3,1 / 2,1)$ & $(1,2,3)$ & $(1,2,3)$ & $(1 / 4,1 / 3,1 / 2)$ & $(3,4,5)$ & $(2,3,4)$ & $(1 / 3,1 / 2,1)$ & $(1 / 3,1 / 2,1)$ \\
\hline B4 & $(1 / 3,1 / 2,1)$ & $(1,2,3)$ & $(1,2,3)$ & $(1,1,1)$ & $(1,1,1)$ & $(3,4,5)$ & $(3,4,5)$ & $(1,2,3)$ & $(7,8,9)$ & $(4,5,6)$ & $(2,3,4)$ & $(1,2,3)$ \\
\hline B5 & $(1 / 4,1 / 3,1 / 2)$ & $(1,2,3)$ & $(1,2,3)$ & $(1,1,1)$ & $(1,1,1)$ & $(4,5,6)$ & $(3,4,5)$ & $(1,2,3)$ & $(6,7,8)$ & $(6,7,8)$ & $(1,2,3)$ & $(1,2,3)$ \\
\hline B6 & $(1 / 4,1 / 3,1 / 2)$ & $(1 / 5,1 / 4,1 / 3)$ & $(1 / 3,1 / 2,1)$ & $(1 / 5,1 / 4,1 / 3)$ & $(1 / 6,1 / 5,1 / 4)$ & $(1,1,1)$ & $(1 / 3,1 / 2,1)$ & $(1 / 6,1 / 5,1 / 4)$ & $(1,2,3)$ & $(1,2,3)$ & $(1 / 5,1 / 4,1 / 3)$ & $(1 / 5,1 / 4,1 / 3)$ \\
\hline B7 & $(1 / 4,1 / 3,1 / 2)$ & $(1 / 4,1 / 3,1 / 2)$ & $(1 / 3,1 / 2,1)$ & $(1 / 5,1 / 4,1 / 3)$ & $(1 / 5,1 / 4,1 / 3)$ & $(1,2,3)$ & $(1,1,1)$ & $(1 / 5,1 / 4,1 / 3)$ & $(2,3,4)$ & $(2,3,4)$ & $(1 / 4,1 / 3,1 / 2)$ & $(1 / 4,1 / 3,1 / 2)$ \\
\hline B8 & $(1,2,3)$ & $(1,2,3)$ & $(2,3,4)$ & $(1 / 3,1 / 2,1)$ & $(1 / 3,1 / 2,1)$ & $(4,5,6)$ & $(3,4,5)$ & $(1,1,1)$ & $(7,8,9)$ & $(6,7,8)$ & $(1,2,3)$ & $(1,2,3)$ \\
\hline B9 & $(1 / 4,1 / 3,1 / 2)$ & $(1 / 8,1 / 7,1 / 6)$ & $(1 / 5,1 / 4,1 / 3)$ & $(1 / 9,1 / 8,1 / 7)$ & $(1 / 8,1 / 7,1 / 6)$ & $(1 / 3,1 / 2,1)$ & $(1 / 4,1 / 3,1 / 2)$ & $(1 / 9,1 / 8,1 / 7)$ & $(1,1,1)$ & $(1 / 3,1 / 2,1)$ & $(1 / 9,1 / 8,1 / 7)$ & $(1 / 9,1 / 8,1 / 7)$ \\
\hline B10 & $(1 / 5,1 / 4,1 / 3)$ & $(1 / 5,1 / 4,1 / 3)$ & $(1 / 4,1 / 3,1 / 2)$ & $(1 / 6,1 / 5,1 / 4)$ & $(1 / 8,1 / 7,1 / 6)$ & $(1 / 3,1 / 2,1)$ & $(1 / 4,1 / 3,1 / 2)$ & $(1 / 9,1 / 8,1 / 7)$ & $(1,2,3)$ & $(1,1,1)$ & $(1 / 7,1 / 6,1 / 5)$ & $(1 / 7,1 / 6,1 / 5)$ \\
\hline B11 & $(1,2,3)$ & $(1,2,3)$ & $(1,2,3)$ & $(1 / 4,1 / 3,1 / 2)$ & $(1 / 3,1 / 2,1)$ & $(3,4,5)$ & $(2,3,4)$ & $(1 / 3,1 / 2,1)$ & $(7,8,9)$ & $(5,6,7)$ & $(1,1,1)$ & $(1,1,1)$ \\
\hline B12 & $(1,2,3)$ & $(1,2,3)$ & $(1,2,3)$ & $(1 / 3,1 / 2,1)$ & $(1 / 3,1 / 2,1)$ & $(3,4,5)$ & $(2,3,4)$ & $(1 / 3,1 / 2,1)$ & $(7,8,9)$ & $(5,6,7)$ & $(1,1,1)$ & $(1,1,1)$ \\
\hline
\end{tabular}

Table 5. Pairwise comparison of barriers in crisp values.

\begin{tabular}{|c|c|c|c|c|c|c|c|c|c|c|c|c|}
\hline & B1 & B2 & B3 & B4 & B5 & B6 & B7 & B8 & B9 & B10 & B11 & B12 \\
\hline B1 & 1 & 0.361111 & 0.611111 & 2 & 3 & 3 & 3 & 0.611111 & 3 & 4 & 0.611111 & 0.611111 \\
\hline B2 & 3 & 1 & 2 & 0.611111 & 0.611111 & 4 & 3 & 0.611111 & 7 & 4 & 0.611111 & 0.611111 \\
\hline B3 & 2 & 0.611111 & 1 & 0.611111 & 0.611111 & 2 & 2 & 0.361111 & 4 & 3 & 0.611111 & 0.611111 \\
\hline B4 & 0.611111 & 2 & 2 & 1 & 1 & 4 & 4 & 2 & 8 & 5 & 3 & 2 \\
\hline B5 & 0.361111 & 2 & 2 & 1 & 1 & 5 & 4 & 2 & 7 & 7 & 2 & 2 \\
\hline B6 & 0.361111 & 0.261111 & 0.611111 & 0.261111 & 0.205556 & 1 & 0.611111 & 0.205556 & 2 & 2 & 0.261111 & 0.261111 \\
\hline B7 & 0.361111 & 0.361111 & 0.611111 & 0.261111 & 0.261111 & 2 & 1 & 0.261111 & 3 & 3 & 0.361111 & 0.361111 \\
\hline B8 & 2 & 2 & 3 & 0.611111 & 0.611111 & 5 & 4 & 1 & 8 & 7 & 2 & 2 \\
\hline B9 & 0.361111 & 0.144841 & 0.261111 & 0.126323 & 0.144841 & 0.611111 & 0.361111 & 0.126323 & 1 & 0.611111 & 0.126323 & 0.126323 \\
\hline B10 & 0.261111 & 0.261111 & 0.361111 & 0.205556 & 0.144841 & 0.611111 & 0.361111 & 0.126323 & 2 & 1 & 0.169841 & 0.169841 \\
\hline B11 & 2 & 2 & 2 & 0.361111 & 0.611111 & 4 & 3 & 0.611111 & 8 & 6 & 1 & 1 \\
\hline B12 & 2 & 2 & 2 & 0.611111 & 0.611111 & 4 & 3 & 0.611111 & 8 & 6 & 1 & 1 \\
\hline
\end{tabular}




\section{Step 3: Defuzzification}

The next step is defuzzification, in which the pairwise comparison of CSR barriers under fuzzy input is converted to crisp values. Many defuzzification methods exist, but in this paper, the centroid method of defuzzification is used because of its greater acceptance in the research realm. The defuzzified pairwise comparison is shown in Table 5.

\section{Step 4: Estimation of global weights}

The global weights of the barriers are estimated based on the replies of the case industrial experts through the arithmetic operations of AHP.

Step 5: Check for consistency

Even though the weights are obtained, there is still a need to check for consistency because all the data used were obtained from human judgments. According to the steps required to check for consistency (already discussed in an earlier section), the consistency ratio obtained in 0.099, which is less than 0.1. According to the consistency check parameters, the obtained results are consistent and reliable.

\section{Step 6: Prioritization of attributes}

After the successful completion of the consistency check, finally, the priorities of the barriers of CSR in textile industry were revealed which is shown in Table 6. Furthermore, the results are explored with the existing literatures and also discussed with the industrial managers, and these discussions and explorations are detailed in upcoming sections.

\section{Results and Discussion}

The aim of this section is to provide the results with the assistance of previous sections, to explore the results, and to compare them with the existing results, and to analyze the differences obtained from both the virtual and the state-of-the-art worlds. The relative weights of the barriers and their priorities are shown in Table 6.

Table 6. Relative weights and rank of barriers.

\begin{tabular}{cccc}
\hline S. No & Barriers of CSR in Textile Industry & Relative Weights & Rank \\
\hline 1 & Lack of stakeholder awareness (B1) & 0.103280618 & 6 \\
2 & Lack of training (B2) & 0.096179398 & 7 \\
3 & Lack of information (B3) & 0.066872214 & 8 \\
4 & Financial constraints (B4) & 0.143896281 & 1 \\
5 & Lack of customer awareness (B5) & 0.139778322 & 2 \\
6 & Lack for concern for reputation (B6) & 0.027863976 & 10 \\
7 & Lack of knowledge (B7) & 0.037647753 & 9 \\
8 & Lack of regulations and standards (B8) & 0.138064174 & 3 \\
9 & Diversity (B9) & 0.015128141 & 12 \\
10 & Company culture (B10) & 0.019338477 & 11 \\
11 & Lack of social audit (B11) & 0.104615384 & 5 \\
12 & Lack of top management commitment (B12) & 0.107335262 & 4 \\
\hline
\end{tabular}


From Table 6, it becomes clear that financial constraints (B4) are the main barrier to the implementation of CSR in Indian textile industries. Lack of customer awareness (B5) and a lack of regulations and standards (B8) hold second and third positions, respectively. The fourth and fifth positions, respectively, are lack of top-level management commitment (B12) and lack of social audit (B11). The remaining barriers are arranged as follows as per their weightage and overall priority: $\mathrm{B} 4>\mathrm{B} 5>\mathrm{B} 8>\mathrm{B} 12>\mathrm{B} 11>\mathrm{B} 1>\mathrm{B} 2>\mathrm{B} 3>\mathrm{B} 7>\mathrm{B} 6>\mathrm{B} 10>\mathrm{B} 9$. It is clear that Barrier (B4), financial constraints, results in the greatest weightage because implementing new tactics and strategies needs initial investments. This expense makes the stakeholders unhappy because they do not wish to promote new strategies unless they can be convinced it is a profitable endeavor. In an Indian context, most of the textile industries are SMEs; there are very few MNCs, and according to Sweeney [14], the main barrier for SMEs in CSR implementation is cost, a finding he revealed by several responses from SME managers. In addition, Arevalo and Aravind [12] argued that a lack of resources, particularly financial resources, has a significant effect in the implementation of CSR strategies; this financial support limits stakeholders from knowing the importance of CSR or its implementation tactics. Another major barrier of CSR revealed from our study is lack of customer awareness: the implementation and motivation of CSR in any organization depends highly on the willingness of the customers, because CSR activities increase product cost. That additional cost is borne by customers, and often customers focus simply on product price rather than on its social impact. In a developing country like India, this lack of customer awareness became a key issue in CSR implementation. Gupta [73] made a comparative study between U.S. and Indian contexts with a focus of customer views in CSR. His results show the willingness of the Indian customer in terms of CSR is comparatively less compared to U.S. customers. Indian customers tend to be less aware of the benefits of CSR, so it would be beneficial for these customers to increase their level of social awareness due to India's high population. Next to customer awareness, government regulations and codes of conduct play a vital role in CSR implementation. The lack of regulation allows the shareholders to focus more on profit rather than on other ethical and moral factors. According to De Neve [7], the lack of codes of conduct is one of the main reasons for the poor CSR implementation particularly in textile industries; he revealed this from the study on Tiruppur garment industry (South Indian region). Another important barrier for the CSR implementation in Indian textile sector is the lack of top-level management support. This barrier is highly influenced by the lack of resources, because top-level management expects the government to provide funding and subsidies for the CSR activities practiced in their firm. Many shareholders are not interested in CSR activities and continue to think that the firm's only aim is to increase profits and to focus only on value-maximizing objectives [74]. While the results of this study significantly coincide with the state-of-the-art research, according to Faisal [13], lack of customer awareness is a prime barrier for CSR implementation. Hence, a contradiction exists between our study and Faisal's results. If this apparent contradiction is explored in more depth, however, it appears that this conflict occurs mainly due to the application sector; Faisal's study was limited to the application of supply chains, whereas our study focused on the whole textile industry including design, marketing, and each and every step of operations. In production, costs will be considered a main criterion, but in terms of a supply chain, customers' willingness and satisfaction were marked as important. Apart from the Faisal's study, most of the studies determined that financial constraints are a main reason for the ineffectiveness of CSR. 
After exploring the results obtained from the existing literature, our research team approached the case managers to get their feedback. Initially, they were resistant, but after several rounds of discussion, one manager stated that most of their shareholders believe that CSR will not benefit their profit margin and are not willing to budget the cost of implementing CSR. Thus, while it may seem that a lack of shareholder awareness is the barrier, an experienced senior manager affirmed a point made by Barnea and Rubin [74], that the shareholders are aware of CSR but are unwilling to spend the money required, so our study's results are correct. This manager further added that there is a need to prove a correlational relationship between the implementation of CSR and a company's profit within an Indian context, and that so far, previous studies have failed to elucidate that relationship.

Our research team suggested that the case industry should provide training and knowledge regarding the benefits of CSR, particularly to top-level management and to all other employees. If management promoted a campaign to help employees understand why CSR benefits not only the company but also the society, they would likely be met with greater acceptance. Because managers often need some external financial support, they should pursue resources from NGOs and government ministries to fund the successful implementation of CSR.

\section{Managerial Implications}

Even though this research serves many implications on science and society, the main contribution is to assist industrial managers to understand the hurdles preventing CSR implementation. With those issues identified, managers are better able to eradicate those barriers and to emphasize their efforts on the most essential barrier. As a result, they can explain the importance of CSR implementation to their top-level management through this study. Furthermore, some useful societal insights are addressed in this study, such as encouraging managers to recognize that long working hours is actually a threat to the textile industry. By reducing the number of long working hours, managers may increase the number of job opportunities, one of the major political issues in many developing countries. This study also provides guidelines that other developing nations such as Brazil, China, and Russia may use to analyze their barriers in CSR implementation. Therefore, this study may be considered a benchmark for industries in developing nations to address their specific, native factors.

\section{Conclusions}

By realizing the importance of CSR, this study evaluates the essential barrier of CSR implementation in Indian textile industries with the assistance of proposed framework. This approach is further illustrated and validated with support from a case industry located in the southern part of India. The Analytical Hierarchy Process (AHP) was adapted as a solution methodology to evaluate the essential barrier of CSR under a fuzzy environment and it was designed to avoid vagueness and uncertainties in the results. Results reveal that financial constraints (B4) comprise the most essential barrier among other common barriers that tend to hinder CSR implementation in Indian textile sectors. The explanations for these results are explored with the combined assistance of feedback from industrial managers and existing literatures. In addition, many studies $[13,61]$ affirmed that there is a huge correlation between the financial status of the firm and its CSR implementation. In this connection, it is revealed that good financial support and investments on CSR will positively increase CSR implementation, and the same 
result is found in our study. Hence, this study's results are validated with those above considerations. In addition to the cost, customer awareness (B5), lack of regulations and standards (B8), and lack of top management support (B12) play a vital role in the implementation of CSR. The above three barriers are very common in developing nations because of their financial and ethical concerns. Beyond these barriers, the remaining common barriers are ranked based on their weights. The study determines that while Indian organizations face many challenges in the implementation of CSR, regardless of the field of application, Indian organizations in general need to travel more to achieve effective implementation of CSR. In this concern, the following preliminary recommendations are made from the study to avoid the barriers exhibited in the implementation of CSR within the Indian textile sector. Three major stakeholder perspectives - government, customer, and management — are identified as follows.

Governmental perspective:

$\checkmark$ Organizations that practice CSR activities should be rewarded with lower taxes, greater subsidies, and through financial assistance by Indian government.

$\checkmark$ Codes of conduct, as well as moral and ethical standards, should be strictly followed by the Indian government with a high concern for transparency.

$\checkmark$ CSR reporting of organizations should be governed with periodic accounting.

$\checkmark$ There is a need to promote public awareness regarding CSR and its core benefits to be sustained through campaigns, workshops, etc.

Customer perspective:

$\checkmark$ Customers should encourage that an organization's product be socially responsible.

$\checkmark$ Customer should increase their willingness to pay a higher price for products that are socially responsible.

Management perspective:

$\checkmark$ Management needs to be concerned about their moral ethics in addition to their profits. They should understand that CSR is a long-term strategy that helps them to stay competitive in the global marketplace.

$\checkmark$ Managers should encourage awareness programs and campaigns to promote CSR and its practices to the employees, partners, and other players in their organizations.

The recommendations cited above offer a preliminary step, and for the most effective implementation, there are additional strategies that need to be followed.

This study establishes that the majority of barriers are interrelated due to a lack of government support. Another fruitful research area would be to explore why the government has not taken a more active role in encouraging CSR implementation throughout the country's industries. Research needs to be conducted to determine why there is a lack of interest among government officials on the adoption of CSR practices, from where these shortcomings arise, and how appropriate steps should be managed.

Even though this study presents some important managerial insights, it is not without its limitations. The main limitation of this study is that it considers a single case industry. In a nation such as India, with its diverse geographies, a future study may wish to collect and examine data from various locations and then to validate those data sets statistically. CSR is a concept that may be interpreted differently from 
person to person, so care needs to be taken to establish a comprehensive definition. Hence, in the future, there is a need to analyze CSR with a broad range of decision makers who have different backgrounds. Overall, the study clearly defines that barriers exist primarily due to the ineffectiveness of multiple stakeholders, because their support impacts barriers in both tangible and intangible directions. When multiple stakeholders weigh in, there will inevitably be various approaches to implementing CSR. Among those multiple stakeholders, the government plays a vital role in CSR implementation, because a majority of barriers are interrelated to the government's disdain and/or lack of support. As suggested, a fruitful research area would be to examine why the government is not more involved or does not pay enough attention to CSR practices in Indian industries. It is time to explore the reasons behind the government's lack of interest, from where the shortcomings arise, and how a much-needed endorsement would be managed.

\section{Acknowledgments}

Kannan Govindan's research is partially supported by a Grant from Forsknings-og Innovationsstyrelsen for project 12-132697.

\section{Author Contributions}

Lixin Shen and Kannan Govindan contributed to the theoretical development, the writing, to refining and strengthening the paper's findings, expositions, and managerial implications, and Madan Shankar contributed to the writing and case study part of the paper. In addition, Kannan Govindan is responsible for conducting the whole research.

\section{Conflicts of Interests}

The authors declare no conflict of interest.

\section{References}

1. Pagell, M.; Krause, D.; Klassen, R. Sustainable supply chain management: Theory and practice. J. Supply Chain Manag. 2008, 44, 85-85.

2. Ageron, B.; Gunasekaran, A.; Spalanzani, A. Sustainable supply management: An empirical study. Int. J. Prod. Econ. 2012, 140, 168-182.

3. Dahlsrud, A. How corporate social responsibility is defined: An analysis of 37 definitions. Corp. Soc. Responsib. Environ. Manag. 2008, 15, 1-13.

4. Hasselhorn, H.M. Work Ability-Concept and Assessment. Germany: University of Wuppertal. Available online: http://wai-netzwerk.uni-wuppertal.de/picture/upload/file/Concept_and_Assessment.pdf (accessed on 11 March 2014).

5. Metzner, R.J.; Fischer, F.M. Fatigue and workability in Brazilian textile companies in different corporate social responsibility score groups. Int. J. Ind. Ergon. 2010, 40, 289-294.

6. Gupta, M.; Hodges, N. Corporate social responsibility in the apparel industry: An exploration of Indian consumers' perceptions and expectations. J. Fash. Market. Manag. 2012, 16, 216-233. 
7. De Neve, G. Power, inequality and corporate social responsibility: The politics of ethical compliance in the South Indian garment industry. Econ. Polit. Wkly. 2009, 44, 63-72.

8. Dash, S.R.; Bhal, K.T.; Udgata, J. Organisational culture and environmental responsibility: A study of textile industry in India. Int. J. Indian Cult. Bus. Manag. 2009, 2, 233-246.

9. Baskaran, V.; Nachiappan, S.; Rahman, S. Indian textile suppliers' sustainability evaluation using the grey approach. Int. J. Prod. Econ. 2012, 135, 647-658.

10. Baskaran, V.; Nachiappan, S.; Rahman, S. Supplier assessment based on corporate social responsibility criteria in Indian automotive and textile industry sectors. Int. J. Sustain. Eng. 2011, 4, 359-369.

11. Lauesen, L.M. CSR in publicly owned enterprises: Opportunities and barriers. Soc. Responsib. J. 2011, 7, 558-577.

12. Arevalo, J.A.; Aravind, D. Corporate social responsibility practices in India: Approach, drivers, and barriers. Corp. Gov. 2011, 11, 399-414.

13. Faisal, M.N. Analysing the barriers to corporate social responsibility in supply chains: An interpretive structural modelling approach. Int. J. Logist. Res. Appl. 2010, 13, 179-195.

14. Sweeney, L. Corporate social responsibility in Ireland: Barriers and opportunities experienced by SMEs when undertaking CSR. Corp. Gov. 2007, 7, 516-523.

15. Garavan, T.N.; Heraty, N.; Rock, A.; Dalton, E. Conceptualizing the behavioural barriers to CSR and CS in organizations: A typology of HRD interventions. Adv. Dev. Hum. Resour. 2010, 12, 587-613.

16. Laudal, T. Drivers and barriers of CSR and the size and internationalization of firms. Soc. Responsib. J. 2011, 7, 234-256.

17. Govindan, K.; Kannan, D.; Shankar, K.M. Evaluating the drivers of corporate social responsibility in the mining industry with multi-criteria approach: A multi-stakeholder perspective. J. Clean. Prod. 2014, doi:10.1016/j.jclepro.2013.12.065.

18. Commission of the European Communities. Available online: http://rade.ec.europa.eu/doclib/docs/ 2006/february/tradoc_127374.pdf (accessed on 10 March 2014).

19. Sen, S. Corporate Social Responsibility in Small and Medium Enterprises: Application of Stakeholder Theory and Social Capital Theory. Ph.D. Thesis, Southern Cross University, Lismore, Australia, 2011.

20. Kumar, D.T.; Palaniappan, M.; Kannan, D.; Shankar, K.M. Analyzing the CSR issues behind the supplier selection process using ISM approach. Resour. Conserv. Recycl. 2014, 92, 268-278.

21. Hartmann, M. Corporate social responsibility in the food sector. Eur. Rev. Agric. Econ. 2011, 38, 297-324.

22. Tallontire, A. CSR and regulation: Towards a framework for understanding private standards initiatives in the agri-food chain. Third World Q. 2007, 28, 775-791.

23. Melewar, T.C.; Akel, S. The role of corporate identity in the higher education sector: A case study. Corp. Commun. 2005, 10, 41-57.

24. Atakan, M.S.; Eker, T. Corporate identity of a socially responsible university-A Case from the Turkish higher education sector. J. Bus. Ethics 2007, 76, 55-68. 
25. Loureiro, S.M.; Sardinha, I.M.D.; Reijnders, L. The effect of corporate social responsibility on consumer satisfaction and perceived value: The case of the automobile industry sector in Portugal. J. Clean. Prod. 2012, 37, 172-178.

26. Fuzi, N.M.; Desa, A.F.N.C.; Hibadullah, S.N.; Zamri, F.I.M.; Habidin, N.F. Corporate social responsibility practices (CSR) and CSR performance in Malaysian automotive industry. Int. J. Account. Financ. Report. 2012, 2, 268-277.

27. Perry, P.; Towers, N. Determining the antecedents for a strategy of corporate social responsibility by small-and medium-sized enterprises in the UK fashion apparel industry. J. Retail. Consum. Serv. 2009, 16, 377-385.

28. Chi, T. Building a sustainable supply chain: An analysis of corporate social responsibility (CSR) practices in the Chinese textile and apparel industry. J. Text. Inst. 2011, 102, 837-848.

29. Cooke, F.L.; He, Q. Corporate social responsibility and HRM in China: A study of textile and apparel enterprises. Asia Pac. Bus. Rev. 2010, 16, 355-376.

30. Leisinger, K.M. The corporate social responsibility of the pharmaceutical industry: Idealism without illusion and realism without resignation. Bus. Ethics Q. 2005, 15, 577-594.

31. Cheah, E.T.; Chan, W.L.; Chieng, C.L.L. The corporate social responsibility of pharmaceutical product recalls: An empirical examination of US and UK markets. J. Bus. Ethics 2007, 76, 427-449.

32. Xia, X.; Govindan, K.; Zhu, Q. Analyzing internal barriers for automotive parts remanufacturers in China using grey-DEMATEL approach. J. Clean. Prod. 2015, 87, 811-825.

33. Von Neumann, J.; Morgenstern, O. Theory of Games and Economic Behavior, 2nd ed.; Princeton University Press: Princeton, NJ, USA, 1947; p. 641.

34. Savage, L.J. The Foundations of Statistics, Second Revised ed.; Wiley: New York, NY, USA, 1954; p. 112.

35. Zavadskas, E.K.; Turskis, Z.; Kildienė, S. State of art surveys of overviews on MCDM/MADM methods. Technol. Econ. Dev. Econ. 2014, 20, 165-179.

36. Stigzelius, I.; Mark-Herbert, C. Tailoring corporate responsibility to suppliers: Managing SA8000 in Indian garment manufacturing. Scand. J. Manag. 2009, 25, 46-56.

37. Mezzadri, A. Indian garment clusters and CSR norms: Incompatible agendas at the bottom of the garment commodity chain. Oxf. Dev. Stud. 2014, 42, 238-258.

38. Zhu, D.; Tan, K.H. Issues and challenges of CSR practices in textile industry: An empirical study in Suzhou, China. Int. J. Manag. Enterp. Dev. 2008, 5, 759-772.

39. Valmohammadi, C. Investigating corporate social responsibility practices in Iranian organizations: An ISO 26000 perspective. Bus. Strategy Ser. 2011, 12, 257-263.

40. Duarte, F.P.; Rahman, S. Perceptions of corporate social responsibility by Bangladeshi managers: An exploratory study. Int. Rev. Bus. Res. Pap. 2010, 6, 119-136.

41. Mont, O.; Leire, C. Socially responsible purchasing in supply chains: Drivers and barriers in Sweden. Soc. Responsib. J. 2009, 5, 388-407.

42. Parisi, C.; Mikkelsen, O.S.; Arlbjørn, J.S. Implementing Corporate Social Responsibility in Supply Chains: Drivers and Barriers. In The 21st Annual Nofoma Conference; Hertz, S., Ed.; Jönköping International Business School: Jönköping, Sweden, 2009; pp. 648-664. Available online: http://forskningsbasen.deff.dk/Share.external?sp=S871fb3f0-57e6-11de-839d-000ea68e967b\&sp= Ssdu (accessed on 9 March 2014). 
43. Pedersen, E.R.G.; Neergaard, P.; Pedersen, J.T.; Gwozdz, W. Conformance and deviance: Company responses to institutional pressures for corporate social responsibility reporting. Bus. Strategy Environ. 2013, 22, 357-373.

44. Goworek, H. Social and environmental sustainability in the clothing industry: A case study of a fair trade retailer. Soc. Responsib. J. 2011, 7, 74-86.

45. Kozar, J.M.; Connell, K.Y.H. Socially and environmentally responsible apparel consumption: Knowledge, attitudes, and behaviors. Soc. Responsib. J. 2013, 9, 315-324.

46. Ha-Brookshire, J.E.; Norum, P.S. Willingness to pay for socially responsible products: Case of cotton apparel. J. Consum. Market. 2011, 28, 344-353.

47. Dickson, M.A.; Eckman, M. Social responsibility: The concept as defined by apparel and textile scholars. Cloth. Text. Res. J. 2006, 24, 178-191.

48. Devinney, T.M. Is the socially responsible corporation a myth? The good, the bad, and the ugly of corporate social responsibility. Acad. Manag. Perspect. 2009, 23, 44-56.

49. Godfrey, P.C.; Hatch, N.W. Researching corporate social responsibility: An agenda for the $21 \mathrm{st}$ century. J. Bus. Ethics 2007, 70, 87-98.

50. Smith, V.; Langford, P. Evaluating the impact of corporate social responsibility programs on consumers. J. Manag. Organ. 2009, 15, 97-109.

51. Öberseder, M.; Schlegelmilch, B.B.; Murphy, P.E. CSR practices and consumer perceptions. J. Bus. Res. 2013, 66, 1839-1851.

52. Times of India, 2013. Available online: http://timesofindia.indiatimes.com/topic/gujarat-pollutioncontrol-board/news/ (accessed on 14 March 2014).

53. Battaglia, M.; Bianchi, L.; Frey, M.; Iraldo, F. An innovative model to promote CSR among SMEs operating in industrial clusters: Evidence from an EU project. Corp. Soc. Responsib. Environ. Manag. 2010, 17, 133-141.

54. Saaty, T.L. The Analytic Hierarchy Process: Planning, Priority Setting, Resources Allocation; McGraw: New York, NY, USA, 1980.

55. Anuar, N.B.; Papadaki, M.; Furnell, S.; Clarke, N. Incident prioritisation using analytic hierarchy process (AHP): Risk Index Model (RIM). Secur. Commun. Netw. 2013, 6, 1087-1116.

56. Borade, A.B.; Kannan, G.; Bansod, S.V. Analytical hierarchy process-based framework for VMI adoption. Int. J. Prod. Res. 2013, 51, 963-978.

57. Govindan, K.; Kaliyan, M.; Kannan, D.; Haq, A.N. Barriers analysis for green supply chain management implementation in Indian industries using analytic hierarchy process. Int. J. Prod. Econ. 2014, 147, 555-568.

58. Dey, P.K.; Cheffi, W. Green supply chain performance measurement using the analytic hierarchy process: A comparative analysis of manufacturing organisations. Prod. Plan. Control 2013, 24, 702-720.

59. Dyer, R.F.; Forman, E.H. Group decision support with the analytic hierarchy process. Decis. Support Syst. 1992, 8, 99-124.

60. Chen, C.T. Extensions of the TOPSIS for group decision-making under fuzzy environment. Fuzzy Sets Syst. 2000, 114, 1-9.

61. Govindan, K.; Diabat, A.; Madan Shankar, K. Analyzing the drivers of green manufacturing with fuzzy approach. J. Clean. Prod. 2014, doi:10.1016/j.jclepro.2014.02.054. 
62. Chang, D.Y. Applications of the extent analysis method on fuzzy AHP. Eur. J. Oper. Res. 1996, 95, 649-655.

63. Haq, A.N.; Kannan, G. Fuzzy analytical hierarchy process for evaluating and selecting a vendor in a supply chain model. Int. J. Adv. Manuf. Technol. 2006, 29, 826-835.

64. Govindan, K.; Khodaverdi, R.; Jafarian, A. A fuzzy multi criteria approach for measuring sustainability performance of a supplier based on triple bottom line approach. J. Clean. Prod. 2013, 47, 345-354.

65. Mahmoudabadi, A.; Seyedhosseini, S.M. Time-risk trade-off of hazmat routing problem under emergency environment by using linguistic variables. Int. J. Adv. Oper. Manag. 2014, 6, 110-130.

66. Pramanik, S.; Jana, D.K.; Maity, K. A multi objective solid transportation problem in fuzzy, bi-fuzzy environment via genetic algorithm. Int. J. Adv. Oper. Manag. 2014, 6, 4-26.

67. Patil, S.K.; Kant, R. Predicting the success of knowledge management adoption in supply chain using fuzzy DEMATEL and FMCDM approach. Int. J. Bus. Perform. Supply Chain Model. 2014, 6, 75-93.

68. Datta, S.; Samantra, C.; Mahapatra, S.S.; Mondal, G.; Chakraborty, P.S.; Majumdar, G. Selection of internet assessment vendor using TOPSIS method in fuzzy environment. Int. J. Bus. Perform. Supply Chain Model. 2013, 5, 1-27.

69. Tseng, M.L.; Wang, R.; Chiu, S.; Antony, F.; Geng, Y.; Lin, Y.H. Improving performance of green innovation practices under uncertainty. J. Clean. Prod. 2013, 40, 71-82.

70. Jindal, A.; Sangwan, K.S. Development of an interpretive structural model of drivers for reverse logistics implementation in Indian industry. Int. J. Bus. Perform. Supply Chain Model. 2013, 5, 325-342.

71. Mudgal, R.K.; Shankar, R.; Talib, P.; Raj, T. Greening the supply chain practices: An Indian perspective of enablers' relationships. Int. J. Adv. Oper. Manag. 2009, 1, 151-176.

72. Şen, C.G.; Çınar, G. Evaluation and pre-allocation of operators with multiple skills: A combined fuzzy AHP and max-min approach. Expert Syst. Appl. 2010, 37, 2043-2053.

73. Gupta, S. Consumer stakeholder view of corporate social responsibility: A comparative analysis from USA and India. Soc. Responsib. J. 2011, 7, 363-380.

74. Barnea, A.; Rubin, A. Corporate social responsibility as a conflict between shareholders. J. Bus. Ethics 2010, 97, 71-86.

(C) 2015 by the authors; licensee MDPI, Basel, Switzerland. This article is an open access article distributed under the terms and conditions of the Creative Commons Attribution license (http://creativecommons.org/licenses/by/4.0/). 